\title{
Life Cycle Assessment of a Compressor Rotor with a Hybrid Analysis Model
}

\author{
Liang Wang ${ }^{1, a}$, Tao $\mathrm{Li}^{2, \mathrm{~b}}$ \\ ${ }^{1}$ Dalian University of Technology, Ganjingzi District, Dalian, Liaoning 116023, China \\ ${ }^{2}$ Dalian University of Technology, Ganjingzi District, Dalian, Liaoning 116023, China \\ azxcvwangliang@163.com, blitao@dlut.edu.cn
}

\begin{abstract}
Keywords: Life cycle assessment; Process analysis; Input-output analysis; Hybrid analysis; Compressor rotor

Abstract. Life cycle assessment is a useful tool to analyze the energy consummation and environmental emissions of the entire life cycle of a product. This paper analyzed the environmental impacts of a compressor rotor in its entire life cycle with an improved tiered hybrid analysis model which combines the process analysis and input-output analysis. Furthermore, the double-counting part was subtracted from the hybrid analysis model through the system incompleteness factor. The results show that primary energy demand (PED) and global warming potential (GWP) are two main environmental impact categories in the life cycle of the compressor rotor. And the usage stage contributes the most environmental impacts because of the large amount of electricity consumed. This study validates the effectiveness of the improved tiered hybrid analysis model. Adding the upstream production stage to the study system by input-output analysis can significantly decrease the truncation errors of process analysis.
\end{abstract}

\section{Introduction}

Energy and environmental problems have become severe challenges for human being in 21th century. Energy conservation and pollution reduction are inevitable choices to keep sustainable development. Currently, manufacturing industry has led to significant environmental impacts, especially in the capital-intensive manufacturing. Based on this, China has made specific energy conservation and pollution reduction policies for several industries including the compressor manufacturing industry [1].

Life cycle assessment (LCA) is a "cradle to grave" method for analyzing and assessing the potential environmental impact and resource utilization of a product throughout its entire life cycle, i.e., from raw materials acquisition, through production and utilization phases, to waste management [2]. ISO 14040 provides a basic framework for LCA including the following four steps: Goal and Scope Definition, Life Cycle Inventory Analysis, Life Cycle Impact Assessment, and Interpretation. LCA has been recognized as a favorable environmental management tool. So far, several LCA methods have been identified including: process analysis, input-output analysis, and hybrid analysis.

Process analysis is a conventional life cycle inventory analysis method involving detailed study of resource utilization and environmental emissions from on-site production, and contributions from suppliers of inputs considered significant by the analyst [3]. Process analysis can provide relatively highly precise inventory results based on the large amount of process-specific data. However, because of the complexity of upstream requirements for suppliers and services, process analysis requires to draw the system boundary for a LCA study.

Input-output analysis (IO-analysis) is a flexible method using national economic data and environmental statistical data. The upstream system boundary of IO-analysis is theoretically relative complete than process analysis. Nevertheless, it can't replace process analysis because of its several inherent drawbacks: firstly, it requires national average economic data which can't reflect the precise inventory for a specific case; secondly, input-output data is usually outdated and too aggregated compared with the specific process data; thirdly, only pre-consumer stages of a product's life cycle are considered in IO-analysis [4]. 
To draw on the primary advantages of both process and IO-analysis, hybrid analysis methods have been proposed and developed [5]. Hybrid analysis approach can significantly extend the system boundary whilst maintaining the detail for LCA studies [6]. Until now, the hybrid analysis method has been widely accepted and applied to a large number of case studies. There are three frequently-used types of hybrid analysis: tiered hybrid analysis, IO-based hybrid analysis, and integrated hybrid analysis. In this paper, we only discuss the tiered hybrid analysis.

Peng et al. [7] analyzed the environmental impacts of a large-scale compressor based on process analysis model. Shi et al. [8] investigated the energy consumption and environmental emissions of a refrigeration compressor using the process analysis method according with ISO 14040/14044 standards. Zanghelini et al. [9] analyzed the waste management life cycle assessment of a reciprocating air compressor. However, these studies about the life cycle assessment of the compressor were all conducted by the single process analysis model which exiting significant truncation error.

The aim of this paper is to analyze the energy consummation and environmental emissions of a compressor rotor in its entire life cycle with an improved tiered hybrid analysis model which combines the process analysis and IO-analysis.

\section{Material and methods}

Process analysis. Process analysis can be distinguished into process flow diagram approach and matrix inversion approach. Process flow diagram has been the most widely practice. In order to analyze the product system easier, life cycle process flow of a product system can be described with the tree structure diagram [10]. The root of the process tree represents the primary system. The subsystem can be seen as the branch of the process tree. The production process tree consists of several layers with the deepening of upstream production stage. The primary system includes the main life cycle phases such as manufacture, usage and end-of-life disposal. The secondary layer includes processes that interact directly with the primary system in the upstream production stage. As a bottom-up analysis method, process analysis is conducted from primary system to subsystem according to the tree structure flow diagram.

IO-analysis. Leontief [11] first introduced the conception of input-output model of the US economy. He later explained how it could be used to analyze 'externalities' such as environmental impacts [12]. The input-output model is based on the assumption that each industry consumes outputs of various other industries in fixed ratios in order to produce its own output. Based on this assumption, the technical coefficient matrix $\boldsymbol{A}$ is defined that each column of matrix $\boldsymbol{A}$ represents domestic intermediate industry outputs in monetary values required to produce one unit of monetary output of another. The total amount of industry output $\boldsymbol{X}$ required by an arbitrary final demand of industry outputs $\boldsymbol{F}$ is calculated by equation [13]:

$$
\boldsymbol{X}=(\boldsymbol{I}-\boldsymbol{A})^{-1} \boldsymbol{F} .
$$

where, $\boldsymbol{I}$ denotes an identity matrix. This input-output model had been further improved remarkably by distinguishing commodities from industry outputs.

Environmental impacts of IO-analysis are based on the assumption that the amount of environmental impacts generated by an industry is proportional to the amount of output of the industry. Hendrickson et al. [14] first proposed the IO-analysis which uses the input-output table and environmental statistics. Therefore, the mathematical model of IO-analysis can be expressed as:

$$
{ }_{10} \boldsymbol{E}=\boldsymbol{R} \boldsymbol{X}=\boldsymbol{R}(\boldsymbol{I}-\boldsymbol{A})^{-1} \boldsymbol{F} .
$$

where, ${ }_{1} \boldsymbol{E}$ is the total domestic direct and indirect environmental impact vector, $\boldsymbol{R}$ is the environmental impact coefficient matrix that shows the amount of pollutants emitted or natural 
resources consumed to produce unit monetary output of each industry, $\boldsymbol{I}, \boldsymbol{A}$ and $\boldsymbol{F}$ are familiar notation from previous discussion.

Hybrid analysis. Bullard and Pillati [15] and Bullard et al. [16] combined process analysis with IO-analysis to calculate the energy consummation of the US economy. Moriguchi et al. [17] first introduced the tiered hybrid analysis to LCA in 1970s. In tiered hybrid analysis, process based data are gathered for the usage phase, disposal phase and some important upstream processes. The pre-consumer phases are modeled by IO-analysis, and the two datasets are simply added together [4]. Therefore, the ordinary mathematical model of tiered hybrid analysis can be expressed as:

$$
{ }_{T H} \boldsymbol{E}={ }_{I O} \boldsymbol{E}+{ }_{P} \boldsymbol{E} .
$$

Where, ${ }_{T H} \boldsymbol{E}$ represent the total environmental impacts from tiered hybrid analysis, ${ }_{1} \boldsymbol{E}$ represent the environmental impacts of pre-consumer phases from IO-analysis, ${ }_{P} \boldsymbol{E}$ represent the environmental impacts of usage phase, disposal phase and some important upstream processes from process analysis.

In tiered hybrid analysis, a pivotal step is selecting an appropriate system interface location which depends on the depth of process analysis. In terms of the specificity of process analysis, the layer of production order should be as deep as possible. However, with the deep-going of process analysis, the double-counting problem in tiered hybrid model becomes seriously. Therefore, the lower-order environmental impacts taken into account in the process based inventory should be subtracted from the input-output inventory according to the depth of the production order layer. An approach developed by Rowley [5] is suitable herein to solve the double-counting problem using the system incompleteness factor.

The IO-analysis model can be expanded to the infinite series:

$$
{ }_{10} E=R(I-A)^{-1} F=R F+R A F+R A^{2} F+R A^{3} F+\mathrm{L} .
$$

where, the first term in the series denotes the environmental impacts of the first production order in the system.

The system incompleteness factor (SIF) for industry sector $j$ and environmental indicator $n$ at production order $k$ can be defined as [5]:

$$
S I F_{j, n, k}=\frac{\boldsymbol{E}_{j, n, \infty}-\boldsymbol{E}_{j, n, k}}{\boldsymbol{E}_{j, n, \infty}}=1-\frac{\boldsymbol{E}_{j, n, k}}{\boldsymbol{E}_{j, n, \infty}} .
$$

where, $\boldsymbol{E}_{j, n, k}$ is the environmental impact of industry sector $j$ and environmental indicator $n$ for first $k$ production orders. We have calculated all the SIF of the 135 China industry sectors on various environmental indicators and production orders.

Therefore, the modified mathematical model of improved tiered hybrid analysis can be expressed as:

$$
{ }_{T H} \boldsymbol{E}=\sum_{k=0}^{K}{ }_{P} \boldsymbol{E}_{k}+\left(\boldsymbol{R} \boldsymbol{A}^{K+1} \boldsymbol{F}+\boldsymbol{R} \boldsymbol{A}^{K+2} \boldsymbol{F}+\mathrm{L}\right)={ }_{P} \boldsymbol{E}+S I F \times{ }_{I O} \boldsymbol{E} .
$$

where, ${ }_{P} \boldsymbol{E}$ represent the environmental impacts before first $K$ orders of production layers from process analysis, ${ }_{I} \boldsymbol{E}$ denotes the environmental impacts after $K$ orders of production layers from IO-analysis, the others are familiar notation from previous discussion. The depth of production orders $K$ in this tiered hybrid model can be estimated through the tree structure flow diagram.

Lenzen [18] demonstrated the system completeness curve of process analysis which indicated the relationship between the system completeness and the order of production layer. The system completeness curve of expanded IO-analysis is the same trend as the process analysis. Therefore, the system completeness curve of tiered hybrid analysis model can be shown as Fig. 1. 


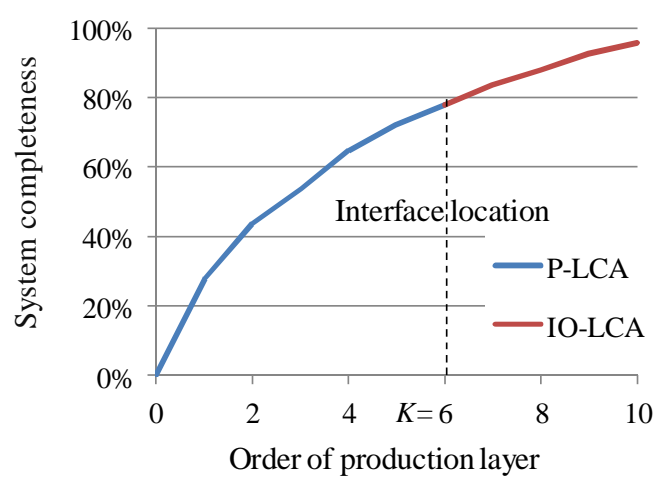

Fig. 1 System completeness curve of tiered hybrid analysis

\section{Goal and scope definition}

Goal of the study. A compressor rotor is selected to quantify the environmental impacts throughout its entire life cycle based on an improved tiered hybrid analysis model. The compressor rotor in this LCA study is a type of PLC803 produced in the Shenyang Blower Work (SBW) Group Co., Ltd. The rated power and output pressure of the gas compressor are $307 \mathrm{~kW}$ and $3 \mathrm{MPa}$, respectively. It is approximately 2 tons weight, and the detail material compositions of the diesel engine by weight are shown in Table 1. The functional unit of this LCA study is defined as the targeted compressor rotor used for 3 years.

\begin{tabular}{lll}
\multicolumn{3}{l}{ Table 1 Main materials of the compressor rotor } \\
\hline Items & Amounts & units \\
\hline Carbon steel & 25.65 & {$[\mathrm{~kg}]$} \\
Stainless steel & 319.85 & {$[\mathrm{~kg}]$} \\
Alloy & 1331.7 & {$[\mathrm{~kg}]$} \\
Electricity & 154270 & {$[\mathrm{kWUh}]$} \\
Compressor rotor & 1867.5 & {$[\mathrm{~kg}]$} \\
Compressor & 1 & {$[\mathrm{set}]$} \\
\hline
\end{tabular}

Scope of the study. Fig. 2 shows the system boundary of the study which spanning whole life cycle of the compressor rotor.

Data collection and source. In process analysis model, the amounts of input requirements are obtained from spot investigation in the SBW about raw materials production, compressor rotor manufacturing, transportation, usage and end-life-disposal. The environmental emissions and resource consummation of unit input flow refers to the Chinese Core Life Cycle Database (CLCD) developed by IKE Corporation and relevant empirical equation [19].

\section{Life cycle inventory analysis}

Upstream production stage. The inventory analysis of the upstream production stage is evaluated with the IO-analysis model in which the technical coefficient matrix $\boldsymbol{A}$ is obtained from the Chinese input-output table of year 2007 applied to 135 sectors [20]. The environmental impact coefficient matrix $\boldsymbol{R}$ is obtained from the China Statistical Yearbook on Environmental and relevant literature [21], which is applied to 26 integrated sectors [22]. According to the depth of the process analysis, the double-counting part is subtracted from the input-output inventory result using the system incompleteness factor. 


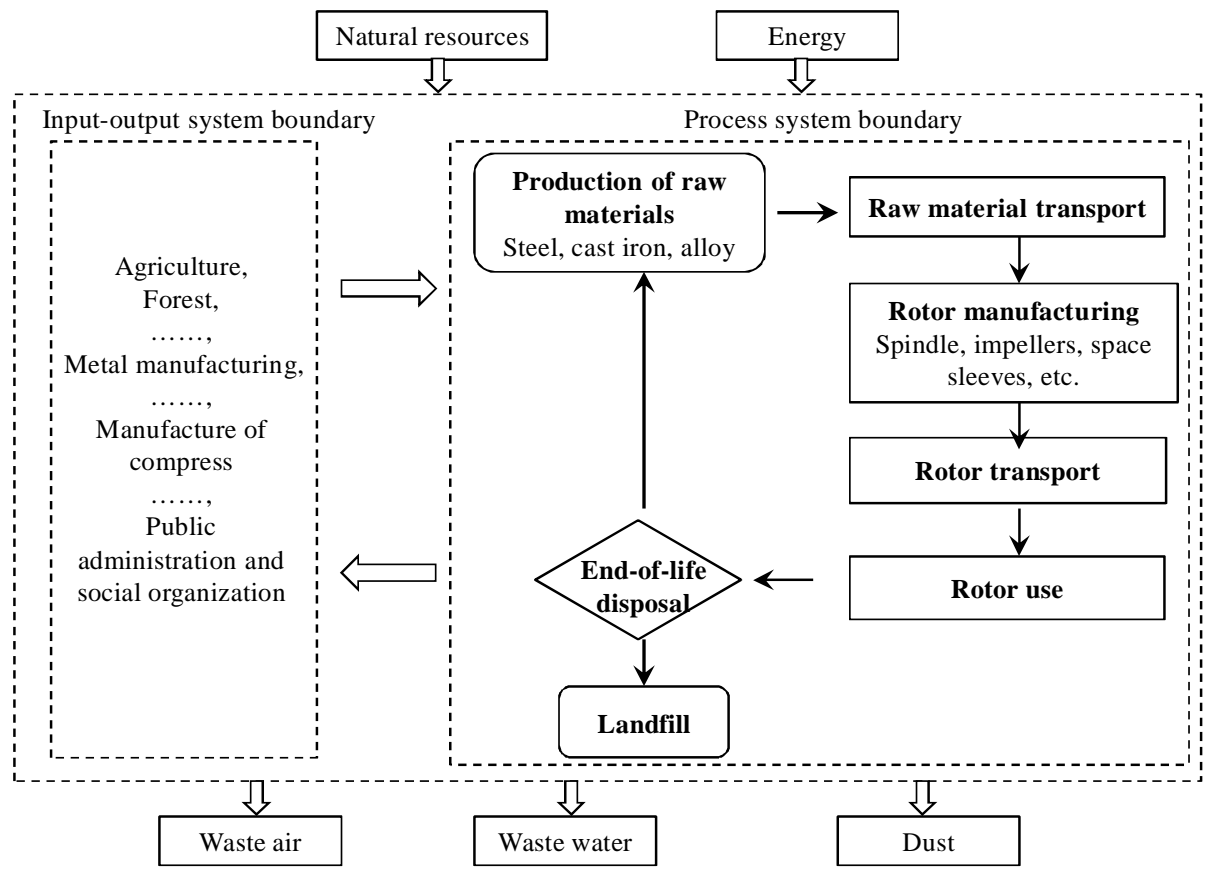

Fig. 2 System boundary of the tiered hybrid analysis

Pre-consumer production stage. The pre-consumer production stage is analyzed with process-based inventory analysis model including raw material production, material transport, components manufacture and compressor rotor transport. The compressor rotor mainly composed by one spindle, three impellers, four space sleeves and one balance plate. Basically, the materials of the components can be divided into: alloy, stainless steel and carbon steel (Table 1). In this study, the raw materials come from Qiqihar City which is $782 \mathrm{~km}$ distance from the Shenyang. The customer of the compressor is in Lanzhou City about $2156 \mathrm{~km}$ distance from the Shenyang. The manufacture procedures of the compressor is complex mainly including rough and finish machining, heat treatment, flaw detection and dynamic balance testing. The energy consumed by these processes is measured by multiplying the power of relevant equipment with working time.

Use and disposal stages. In the usage stage, large amount of electricity is consumed because of the high-rated power and long time running. The electricity consumption can be calculated by multiplying the operation power with service life of the compressor rotor. The recycling and landfill are used to dispose the discarded compressor rotor. Relevant literature data demonstrated that $61.7 \%$ of steel are recycled for remelting and $38.3 \%$ are deposited in landfills [23]. The energy consummation in the recycling phase can be calculated by multiplying the power of metal furnace with the working time.

The corresponding energy consummation and environmental emissions of the entire life cycle of the compressor rotor are summarized in Table 2.

Table 2 LCA inventory of the compressor rotor

\begin{tabular}{|c|c|c|c|c|c|c|}
\hline \multirow{2}{*}{$\begin{array}{l}\text { Substance } \\
{[\mathrm{kg}]}\end{array}$} & \multirow{2}{*}{$\begin{array}{l}\text { IO-analysis } \\
\text { (Upstream ) }\end{array}$} & \multicolumn{4}{|c|}{ Process analysis } & \multirow{2}{*}{$\begin{array}{l}\text { Hybrid analysis } \\
\text { (Total) }\end{array}$} \\
\hline & & Pre-consumer & Use & Disposal & Subtotal & \\
\hline ce & 32552.79 & 93200.00 & 3220000.0 & 1391.00 & 3314591.00 & 3347143.79 \\
\hline $\mathrm{CO}_{2}$ & 86221.79 & 197628.00 & 7250000.0 & 2930.00 & 7450558.00 & 7536779.79 \\
\hline $\mathrm{SO}_{2}$ & 242.09 & 595.00 & 23100.0 & 8.67 & 23703.67 & 23945.76 \\
\hline $\mathrm{NO}_{\mathrm{x}}$ & 213.81 & 575.50 & 21200.0 & 9.07 & 21784.57 & 21998.38 \\
\hline $\mathrm{CH}_{4}$ & 277.90 & 562.80 & 20300.0 & 8.58 & 20871.38 & 21149.28 \\
\hline Dust & 76.63 & 19572.0 & 834000.0 & 316.00 & 853888.0 & 853964.63 \\
\hline COD & 35.53 & 80.70 & 532.0 & 0.31 & 613.01 & 648.54 \\
\hline
\end{tabular}




\section{Life cycle impact assessment}

The life cycle impact assessment is a way to interpret how the processes and products impact the environment. In general, life cycle impact assessment includes the following steps: Classification, Characterization, and Normalization. In this study, the environmental impact is analyzed according to CML 2001 method proposed by Guinee et al. [24]. Four environmental impact categories are selected: primary energy demand (PED), global warming potential (GWP), acidification potential (AP), eutrophication potential (EP).

Characterization models the life cycle inventory results within impact categories using characterization factors. The characterization factors used in the LCA study are referred to GBT2589-2008, IPCC2007 and CML2002. Normalization is used to express potential impacts in a way that can be compared among impacts categories on the basis of a selected reference value. The normalization reference value selected in this study is cited from Wenzel et al. [25]. The corresponding normalization results of different life cycle stages are shown in Table 3.

Table 3 Detailed environmental impacts in different life cycle stages

\begin{tabular}{llllllll}
\hline Impact & IO-analysis & \multicolumn{2}{l}{ Process analysis } & & & Hybrid & $\begin{array}{l}\text { Percentages } \\
\text { category }\end{array}$ \\
\cline { 3 - 6 } (Upstream) & Pre-consumer & Use & Disposal & Subtotal & analysis & of the total \\
\hline PED & 39.31 & 112.56 & 3888.89 & 1.68 & 4003.13 & 4042.44 & $55.0 \%$ \\
GWP & 18.57 & 45.50 & 1671.44 & 0.70 & 1717.64 & 1736.21 & $23.6 \%$ \\
AP & 10.88 & 27.72 & 1053.89 & 0.42 & 1082.03 & 1092.91 & $14.9 \%$ \\
EP & 4.79 & 12.83 & 463.59 & 0.20 & 476.62 & 481.41 & $6.5 \%$ \\
\hline
\end{tabular}

\section{Results and discussion}

The percentages of the environmental impact categories in Table 3 are depicted in Fig. 5. PED is the predominant environmental impact indicator accounts for $55 \%$ of the total environmental impacts. This was primarily due to the large amounts of electricity consumed in the usage stage. GWP constitutes $23.6 \%$ and ranks the second because of large amount of $\mathrm{CO}_{2}$ are generated. AP shares at the 14.9\%. The smallest proportion was contributed by EP (6.5\%) given little emissions of $\mathrm{NO}_{\mathrm{x}}$ and COD.

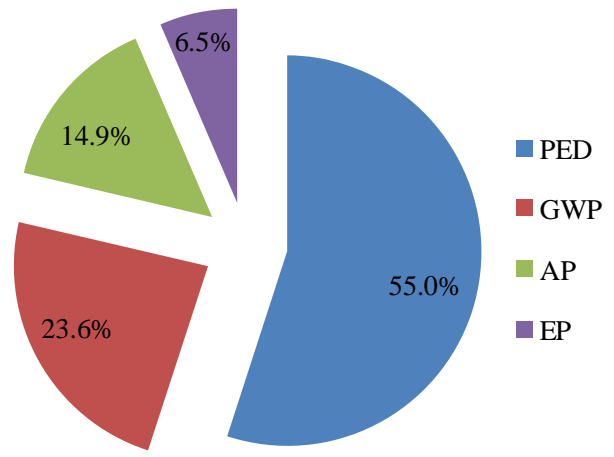

Fig. 3 Normalization result of four environmental impact categories share

The detailed environmental impacts in different life cycle stages in Table 3 are shown in Fig. 4 on a log scale. Fig. 4 shows that the environmental impacts in the usage stage are significantly higher than other life cycle stages of the compressor rotor due to the large amount of electricity consummation. The electricity is almost all generated from thermal power which can release large amounts of environmental emissions. This validated the conclusion made by Peng et al. [7] that the environmental impacts in the use stage can exceed the both raw material production and manufacturing stage. Therefore, a good approach to reduce the environmental impacts is to optimizing the power structure such as increasing the hydropower and wind power. The end-life-disposal stage exerts the least environmental impacts because of low requirement of electricity. The environmental impacts of 
upstream production stage are slightly lower than the pre-consumer production stage. This demonstrates that the single process analysis can bring remarkable truncation errors.

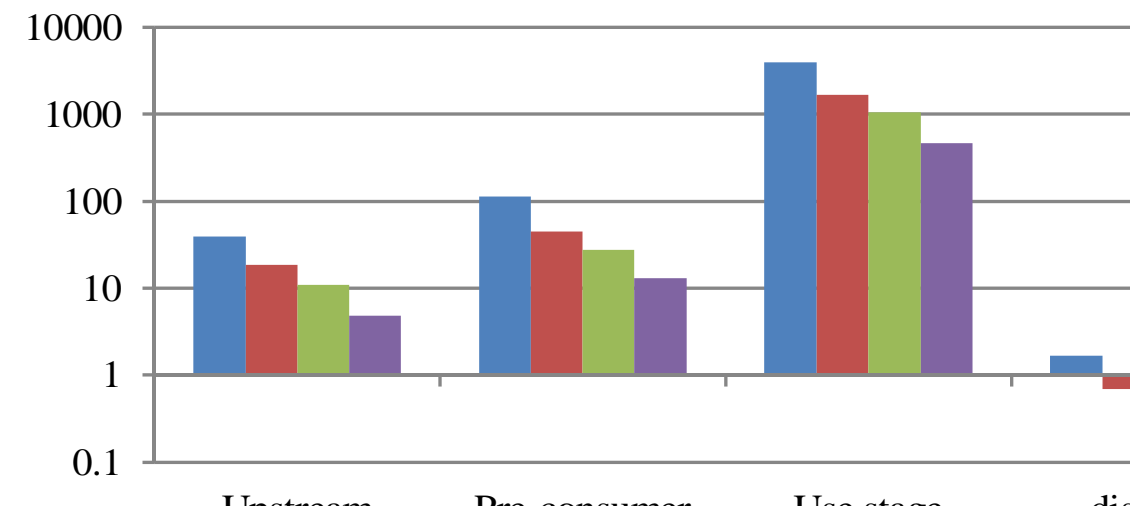

Fig. 4 Log scale results of environmental impacts by life cycle stages

\section{Conclusions}

This study analyzed the energy consummation and environmental emissions of a compressor rotor manufactured by SBW based on an improved tiered hybrid LCA model. The system boundary of this LCA model is relatively complete covering the entire life cycle of the compressor rotor.

The environmental impact results indicate that PED is the predominant impacts, followed by GWP, EP and AP, respectively. The usage stage contributes the most environmental impacts because of the large amount of electricity consummation. A good approach to reduce the environmental impacts is to optimizing the power structure such as increasing the hydropower and wind power. This LCA results can provide the scientific basis for energy conservation and pollution reduction in compressor manufacturing industry.

This study also validates the effectiveness of the improved tiered hybrid analysis model. Adding the upstream production stage to the study system by IO-analysis can significantly decrease the truncation errors.

\section{Acknowledgements}

The authors gratefully acknowledge the support from the National Basic Research Program of China (Grant No. 2011CB013406). The authors would like to thank the SBW Corp. Ltd, Liaoning Province, for providing data support.

\section{References}

[1] Information on http://www.gov.cn/zwgk/2013-02/17/content_2333161.htm

[2] Environmental Protection Agency (EPA): Life cycle assessment: principles and practice, Cincinnati, OH, USA (2006)

[3] S. Suh, M. Lenzen, G.J. Treloar, H. Hondo , A. Horvath , G. Huppes, O. Jolliet, U. Klann, W. Krewitt, Y. Moriguchi, J. Munksgaard, G. Norris: Environmental Science \& Technology, 38(3), 657-664 (2004)

[4] S. Suh and G. Huppes: Journal of Cleaner Production, 13(7), 687-697 (2005)

[5] H.V. Rowley, S. Lundie and G.M. Peters: International Journal of Life Cycle Assessment, 14(6), 508-516 (2009)

[6] R. Heijungs and S. Suh: The computational structure of life cycle assessment, Centre of Environmental Science, Leiden University, Holland. (2001) 
[7] S. Peng, T. Li, M. Dong, J. Shi and H. Zhang: Journal of Cleaner Production, 139, 810-820 (2016)

[8] J. Shi, T. Li, H. Zhang, S. Peng and Z. Liu: International Journal of Life Cycle Assessment, 20, 947-956 (2015)

[9] G.M. Zanghelini, E. Cherubini, P. Orsi and S.R. Soares: Journal of Cleaner Production, 70: 164-174 (2014)

[10] A.M. Tillman, T. Ekvall and H. Baumann: Journal of Cleaner Production, 2(1), 21-29 (1994)

[11] W. Leontief: The structure of the American economy, 1919-1939. Oxford University Press, New York (1941)

[12] W. Leontief: The Review of Economics and Statistics, 52(3), 262-271 (1970)

[13] S. Suh: Ecological Economics, 48(4), 451-467 (2004)

[14] C.T. Hendrickson, L.B. Lave and H.S. Matthews: Environmental life cycle assessment of goods and services: an input-output approach, Resources for the Future, Washington, D.C. (2006)

[15] C.W. Bullard and D.A. Pilati: Reducing uncertainty in energy analysis, University of Illinois, Urbana (1976)

[16] C.W. Bullard, P.S. Penner and D.A. Pilati: Resource and Energy, 1(3), 267-313 (1978)

[17] Y. Moriguchi, Y. Kondo and H. Shimizu: Industry and Environment 16(1), $42-45$ (1993)

[18] M. Lenzen: Journal of Industry Ecology, 4(4), 127-148 (2000)

[19] V.M. Smith, G.V. Keoleian: Journal of Industrial Ecology, 8(1-2), 193-221 (2004)

[20] Information on http://www.stats.gov.cn/english (2007)

[21] G.Q. Chen and B. Zhang: Energy Policy, 38, 6180-6193 (2010)

[22] National Bureau of Statistics of China: China Statistical Yearbook on Environment, China Statistics Press, Beijing (2008)

[23] B. Greening and A. Azapagic: Energy, 39, 205-217 (2012)

[24] J.B. Guinee, M. Gorree, R. Heijungs, G. Huppes, R. Kleijin and A. Koning: Handbook on life cycle assessment: operational guide to the ISO Standarks, Kluwer Academic Publishers, Dordrecht (2002)

[25] H. Wenzel, M.Z. Hauschild and L. Alting: Environmental assessment of products: Col.1/ Methodology, tools and case studies in product development, Chapman \& Hall, London (1997) 